\title{
Apuntes sobre la autoridad de la res iudicata en la jurisprudencia del Tribunal de Justicia de la Unión Europea ${ }^{1}$
}

\author{
Notes on the autorithy of res iudicata in the European Court \\ of Justice case law
}

\author{
Joaquín Sarrión Esteve \\ Investigador Ramón y Cajal \\ Universidad Nacional de Educación a Distancia \\ jsarrion@der.uned.es
}

Sumario: I. Introducción. La primacía como dovela central de la arquitectura del ordenamiento jurídico de la UE.-II. Los principios de autonomía procesal y de seguridad jurídica. 1. El principio de autonomía procesal en la jurisprudencia del Tribunal de Justicia. 2. El principio de seguridad jurídica en la jurisprudencia del Tribunal de Justicia. - III. La cosa juzgada como límite a la primacía y efectividad del Derecho de la UE. 1. Concepto y aproximación a la fuerza de cosa juzgada (res iudicata), y las líneas jurisprudenciales del Tribunal de Justicia sobre la misma. 2. La ponderación casuística entre primacía y efectividad del derecho de la UE y la fuerza de cosa juzgada.-IV. Consideraciones finales.

Resumen: El principio de seguridad jurídica tiene, como una de sus manifestaciones características, dentro del Estado de Derecho, la fuerza de cosa juzgada (res iudicata) que se atribuye a las sentencias o resoluciones judiciales equivalentes firmes, y que implica tanto su impugnabilidad como su potencial influencia en litigios posteriores que guarden una conexión con el asunto ya resuelto en firme. Sin embargo, es posible que estas decisiones judiciales firmes de jueces nacionales, por diversas causas (error, omisión, interpretación manifiestamente contraria, etc.) vulneren el Derecho de la Unión Europea y, por tanto, afecten tanto a su primacía como a su efectividad en sus relaciones con los

${ }^{1}$ El autor agradece el apoyo del Programa Erasmus+ de la Unión Europea en el marco del Módulo Jean Monnet EU Jurisdiction and proccedings (EUJuris), ref. RYC-621025-EPP1-2020-1-ES-EPPJMO-MODULE; y la Ayuda del Programa «Ramón y Cajal» (RYC) 2015 , ref. RYC-2015-18821(FSE/AGENCIA ESTATAL DE INVESTIGACIÓN). Asimismo, agradece los comentarios y observaciones de los evaluadores anónimos. El trabajo manifiesta únicamente las opiniones del autor; ni la Agencia ni la Comisión Europea son responsables de cualquier utilización del contenido del trabajo. 
ordenamientos jurídicos nacionales. El Tribunal de Justicia ha tenido oportunidad de enfrentarse al dilema de ponderar el principio de fuerza de cosa juzgada con las primacía y efectividad del Derecho de la Unión en diversas sentencias. Este trabajo tiene como objetivo realizar una aproximación y revisar la jurisprudencia más importante al respecto hasta la actualidad.

Palabras clave: Cosa juzgada, res iudicata, seguridad jurídica, primacía, efectividad del Derecho de la UE

Abstract: The principle of legal certainty has, as one of its characteristic manifestations, within the rule of law, the force of res judicata that is attributed to the final judgements or equivalent resolutions, which imply that it is not impugnable and also its potential influence on other cases with a connection to the matter already settled. However, it is possible that these final judicial decisions of national judges, for various reasons (error, omission, a manifestly contrary interpretation, etc.) violate the European Union law and, therefore, affect both its primacy and effectiveness in the relations with national legal systems. The European Court of Justice had the opportunity to confront the dilemma of balancing the principle of res judicata with the primacy and effectiveness of EU law in several cases. This work aims to develop an approximation and review of the most important cases related to this balance until today.

Keywords: Res iudicata, legal certainty, primacy, EU law effectiveness.

\section{Introducción. La primacía como dovela central de la arquitectura del ordenamiento jurídico de la UE}

Desde muy pronto, el Tribunal de Justicia llevó acabo lo que se podría denominar como un proceso de constitucionalización del antiguo derecho comunitario $^{2}$, a través de la proclamación con autoridad de principios que se han calificados como constitucionales ${ }^{3}$, como son los principios de autonomía, efecto directo y primacía ${ }^{4}$; atribuyendo, por tanto, al ordenamiento jurídico europeo el carácter de un ordenamiento constitucionalizado que si bien es derecho internacional también, al mismo tiempo, es algo más ${ }^{5}$, un

2 Joaquín Sarrión Esteve, «La constitucionalización sustantiva del Derecho comunitario y su sistema de fuentes», Revista General de Legislación y Jurisprudencia, n. ${ }^{\circ}$ 4, (2007): 631-646.

${ }^{3}$ Giuseppe De Vergottini, Más allá del diálogo entre tribunales (Madrid: Civitas, 2010), 124.

4 Asuntos C-26/62, Van Gend \&Loos, Sentencia del Tribunal de Justicia de 5 de febrero, EU:C:1963:1; y C-6/64, Costa, Sentencia del Tribunal de Justicia de 15 de julio de 1964, EU:C:1964:66.

5 Stephen Weatherill, Law and Values in the European Union (Oxford: Oxford University Press, 2016), 153-154. 
espacio de derecho supranacional por su capacidad de producir efectos posteriores, a nivel interno, al margen incluso de la voluntad inicial de los Es$\operatorname{tados}^{6} \mathrm{o}$, en definitiva, un ordenamiento sui generis ${ }^{7}$.

Sin duda, el principio de primacía es una dovela central en la arquitectura del ordenamiento jurídico de la Unión Europea que posibilita su efectividad y, por tanto, también los derechos de los ciudadanos conferidos por el mismo ${ }^{8}$; pues sirve como criterio de resolución de los eventuales conflictos que surjan entre sus normas y las normas nacionales, dentro de las relaciones entre el ordenamiento europeo y el ordenamiento nacional en el que el primero se integra.

Ciertamente, como se advertido con precisión ${ }^{9}$, la primacía del derecho de la UE se manifiesta en dos vertientes: una normativa (conflicto abstracto), y otra aplicativa (conflicto concreto), ésta última se produce cuando en un caso concreto hay que elegir entre la aplicación del derecho europeo, y la norma nacional, y el operador jurídico, sea juez nacional o incluso la Administración ${ }^{10}$, una vez determinado que no es posible la interpretación conforme, y tratándose de la aplicación de una disposición europea con efecto directo, debe proceder a inaplicar (desplazar) la disposición nacional, con independencia de su naturaleza ${ }^{11}$, y de su carácter temporal anterior o posterior a la disposición europea ${ }^{12}$; también se puede explicar el juego de

${ }^{6}$ Jorge Alguacil Nogueroles, «Ponderación, proporcionalidad y margen de apreciación en la jurisdicción europea de los derechos», Revista General de Derecho Europeo, n. ${ }^{\circ} 25$ (2011): 3.

${ }^{7}$ Ricardo Alonso García, Las sentencias básicas del Tribunal de Justicia de la Unión Europea (Madrid: Civitas, 2015, 5. . Edición), 21-22.

${ }_{8}$ Evidentemente hay otros principios de indudable relevancia en esta arquitectura, como son los principios de autonomía o efecto directo antes citados, o también los principios de interpretación conforme (Asunto C-106/89, Marleasing, Sentencia del Tribunal de Justicia de 13 de diciembre de 1990, EU:C:1990:395), o la responsabilidad patrimonial de los Estados miembros por infracción del Derecho de la UE (Asuntos C-6/90 y C-9/90, Francovich y Bonifaci, Sentencia del Tribunal de Justicia de 19 de noviembre de 1991, EU:C:1991:428).

9 Sigo aquí a Daniel Sarmiento, El Derecho de la Unión Europea (Madrid: Marcial Pons, 2016), 314 y ss.

10 Véase Asunto C-103/88, Fratelli Costanzo, Sentencia del Tribunal de Justicia de 22 de junio de 1989, EU:C:1989:256, apartado 32. Abarcando tanto las disposiciones administrativas de carácter general como las resoluciones administrativas individuales y concretas, véase Asunto C-224/1997, Ciola, Sentencia del Tribunal de Justicia de 29 de abril de 1999, EU:C:1999:212, apartado 32.

11 Por tanto, también respecto a normas constitucionales, véase Asunto C-11/70, Internationale Handelsgesellschaft, Sentencia del Tribunal de Justicia de 17 de diciembre de 1970 , EU:C:1970:114; y Asunto C-399/11, Melloni, Sentencia del Tribunal de Justicia de 26 de febrero de 2013, EU:C:2013:107.

12 No estando el juez nacional obligado a esperar la modificación, derogación o anulación de la disposición nacional, ya sea por procedimientos legislativos o judiciales. Véase Asunto C-106/77, Simmenthal, Sentencia del Tribunal de Justicia de 9 de marzo de 1978, EU:C:1978:49, apartado 24 . 
la primacía, en definitiva, con los llamados efectos de exclusión (se impide la aplicación de la norma nacional contraria), y de sustitución (se aplica la norma europea en sustitución de la norma nacional ${ }^{13}$. Caso distinto es si la disposición europea no tiene efecto directo, y la interpretación conforme de la norma nacional no es posible, pues en este caso no es posible dejar de aplicar la norma nacional, se produce un sacrificio de la primacía ${ }^{14}$, y la efectividad del derecho europeo requiere o abre la puerta a la responsabilidad patrimonial del Estado por infracción del derecho de la Unión ${ }^{15}$.

Todo esto sin perjuicio de la obligación del Estado de, en aras de salvaguardar la seguridad jurídica, proceder a la modificación, anulación o derogación de la norma nacional incompatible, es decir, a su expulsión en definitiva del ordenamiento jurídico ${ }^{16}$. Esto quedaría en manos del Estado, conforme al principio de autonomía institucional y procedimental, al que nos aproximamos en el siguiente apartado.

También resulta importante decir que el conflicto puede constatarse a consecuencia de una interpretación de la norma comunitaria que realiza el Tribunal de Justicia, cuyos efectos interpretativos, al esclarecer y precisar el significado y alcance de la norma europea serían ex tunc, es decir, desde el momento de entrada en vigor de la norma, y no desde el pronunciamiento judicial, extendido su proyección hacia las relaciones surgidas por tanto con antelación a la precisión del significado de la norma ${ }^{17}$.

Interesa señalar, además, que el eventual conflicto a resolver por el operador jurídico, no se produce únicamente entre normas o disposiciones de carácter general, pues la primacía se proyecta no solo sobre normas de

13 Véase en este sentido el trabajo de Antonio López Escudero, «Primacía del Derecho de la Unión Europea y sus límites en la jurisprudencia reciente del TJUE», Revista de Derecho Comunitario Europeo, n. ${ }^{\circ}$ 64, (2019): 795-796.

14 Ibid., 805.

15 Daniel Sarmiento, El Derecho de la Unión Europea, op. cit., 272.

16 En este sentido, Ricardo Alonso García, Las sentencias básicas del Tribunal de Justicia de la Unión Europea, op . cit., 92. Y si bien esto quedaría en manos del Estado, conforme al principio de autonomía institucional y procedimental, por la inexistencia de una competencia de la UE en esta materia, no es menos cierto que este principio está funcionalizado y puede ser objeto de control por el Tribunal de Justicia para garantizar el llamado «efecto útil» del Derecho de la UE. Véase Diana-Urania Galetta, Procedural Autonomy of EU Member States: Paradise Lost? (Verlag Berlin Heidelberg: Springer, 2010), 122.

17 Véase Asunto C-61/79, Denkavit italiana, Sentencia del Tribunal de Justicia de 27 de marzo de 1980, EU:C:1980:100, apartado 16; y Asunto C-50/96, Deutsche Telekom, Sentencia del Tribunal de Justicia de 10 de febrero de 2000, EU:C:2000:72, apartado 43. Y es que las sentencias del Tribunal de Justicia son de carácter declarativo y no constitutivo, véase Asunto C-137/94, Richardson, Sentencia del Tribunal de Justicia de 19 de octubre de 1995 , EU:C:1995:342, apartado 33. 
carácter general, sino también sobre actos de contenido jurídico ${ }^{18}$ y resoluciones judiciales ${ }^{19}$; y son precisamente estas últimas las que nos interesan, ahora, aquí.

\section{Los principios de autonomía procesal y seguridad jurídica}

\section{El principio de autonomía procesal en la jurisprudencia del Tribunal de Justicia}

El principio de autonomía procesal, tal y como se configura, desde los casos Rewe y Comet en $1976^{20}$, implica que son los Estados a quienes corresponde la configuración nacional de sus respectivas normas de procedimiento. Esto es así porque estamos ante una materia sobre la que, en principio, no existe una competencia de la UE, que es el presupuesto de aplicación del principio de autonomía procedimental, lo que si bien podría considerarse como una prueba de que el derecho de la UE depende, para ser efectivo, del derecho procesal nacional ${ }^{21}$, en la otra cara de la moneda se puede considerar que estamos ante un principio funcional, que es utilizado por el Tribunal de Justicia para garantizar el llamado 'efecto útil' del derecho europeo ${ }^{22} \mathrm{o}$, en otras palabras, instrumentalizado, por lo que no habría en sentido propio una elección libre o autónoma estatal sino orientada ${ }^{23}$.

Lo cierto, en cualquier caso, es que conforme al principio de cooperación leal (art. 4.3 del Tratado de la Unión Europea) los Estados miembros deben adoptar todas las medidas que sean apropiadas para asegurar el cumplimiento de las obligaciones derivadas de los Tratados o bien resultantes de los actos de las instituciones europeas, absteniéndose de toda medida que pueda poner en peligro que la Unión consiga sus objetivos; lo que, no nos engañemos, implica obligaciones para el operador jurídico a nivel in-

18 Así, por ejemplo, los actos administrativos. Véase Asunto C-453/00, Kühne \& Heitz, Sentencia del Tribunal de Justicia de 13 de enero de 2004, EU:C:2004:17.

19 Asunto C-234/04, Kapferer, Sentencia del Tribunal de Justicia de 16 de marzo de 2006, EU:C:2006:178.

${ }^{20}$ Véase al respecto Asunto C-33/76, Rewe, Sentencia del Tribunal de Justicia de 16 de diciembre de 1976, EU:C:1976:188; y Asunto C-45/76, Comet, Sentencia del Tribunal de Justicia de 16 de diciembre de 1976, EU:C:1976:191.

${ }^{21}$ Rolf Ortlep, y Maartje Verhoeven, «The principle of primacy versus the principle of national procedural autonomy», NALL, abril-junio, 2012, 2, DOI:10.5553/NALL/.000004.

22 Diana-Urania Galetta, Procedural Autonomy of EU Member States: Paradise Lost?, op. cit., 122 .

23 Xavier Arzoz Santisteban, «La autonomía institucional y procedimental de los Estados miembros en la Unión Europea: Mito y Realidad», Revista de Administración Pública, n. ${ }^{\circ} 191$ (2014): 197. 
terno, que deberá proporcionar y garantizar una tutela adecuada de los derechos derivados del ordenamiento europeo, condicionando así el principio de autonomía procesal ${ }^{24}$.

Por ello, esta facultad de configuración no es absoluta, puesto que se debe garantizar como hemos dicho, el efecto útil del derecho de la Unión, esto es, se debe posibilitar la garantía de los derechos derivados del ordenamiento europeo; y la jurisprudencia del Tribunal de Justicia, cuando resuelve un caso a través del principio de autonomía procesal lo condiciona a los principios de equivalencia (la regulación nacional para hacer efectivos los derechos derivados del ordenamiento europeo de no debe ser menos favorable que las que regulan acciones nacionales similares) y de efectividad (no debe hacer imposible en la práctica o excesivamente difícil el ejercicio de los derechos conferidos) $)^{25}$.

Además, los tribunales nacionales deben interpretar «en la medida de lo posible» las normas procesales para que su aplicación contribuya al objetivo de garantizar la protección judicial efectiva de los derechos de la legislación de la UE atribuidos a los litigantes; de forma que la autonomía procesal estaría fuertemente sostenida por los principios de equivalencia y efectividad, cambiando la antigua libertad procesal a una autonomía limitada.

Pero, aunque se pueda sostener que el Tribunal de Justicia trata de eludir la tensión inherente entre los principios de primacía (que implica desplazamiento) y autonomía procesal con los requisitos de equivalencia y efectividad, optando por uno u otro a la hora de resolver los casos que se le plantean ${ }^{26}$, lo cierto es que al final se producen casos en los que necesariamente ambos principios deben ser objeto de consideración, y por tanto, de ponderación aunque ésta sea implícita, se opte por un camino u otro.

En Simmenthal, el principio de primacía conlleva que el derecho comunitario con efecto directo hace inaplicable de pleno derecho cualquier disposición contraria, y ello es compatible con el principio de cooperación leal para que los Estados miembros proporcionen la protección jurídica efectiva de los derechos derivados del ordenamiento europeo, siendo incompatible toda disposición o práctica, legislativa, administrativa o judicial, que redujera la eficacia del ordenamiento comunitario ${ }^{27}$; es decir, que la primacía

${ }^{24}$ Joaquín Sarrión Esteve, «El Tribunal de Justicia de la Unión Europea y la protección del consumidor en la crisis financiera», Federalismi.it. Rivista di Diritto Pubblico Italiano, Comparato, Europeo, n. ${ }^{\circ} 13$ (2020): 126.

${ }_{25}$ Asunto C-432/05, Unibet, Sentencia del Tribunal de Justicia de 13 de marzo de 2007, EU:C:2007:163.

${ }^{26}$ Rolf Ortlep, y Maartje Verhoeven, «The principle of primacy versus the principle of national procedural autonomy», op. cit., 2.

27 Asunto C-106/77, Simmenthal, cit., apartados 17-23. 
tiene una proyección clara sobre la normativa procesal, como se evidencia también en Factortame, donde se faculta al juez nacional para garantizar la eficacia de una resolución judicial sobre derechos derivados del ordenamiento europeo excluyendo la aplicación de una norma nacional que impide la adopción de medidas provisionales ${ }^{28}$.

Esto, lógicamente tiene consecuencias para la seguridad jurídica, que también es un principio relevante para el propio ordenamiento jurídico europeo.

\section{El principio de seguridad jurídica en la jurisprudencia del Tribunal de Justicia}

La seguridad jurídica, a pesar de su significando cambiante, es un principio inherente del Estado de Derecho, un principio constitucional de los Estados miembros, así como un principio fundamental en el Derecho de la UE y en otros sistemas jurídicos transnacionales ${ }^{29}$, y si bien como tal no está regulado de forma expresa en los $\operatorname{Tratados}^{30}$, el propio Tribunal de Justicia lo ha configurado como un principio general - fundamental- del derecho de la UE, como parte de su ambición para superar las limitaciones de los tratados, y determinación para ejercer el control del ejercicio del poder $)^{31}$, aunque además de como principio general paradigmático del Derecho UE, opera también como límite a la plena aplicación del mismo ${ }^{32}$.

28 Asunto C-213/89, Factortame y otros, Sentencia del Tribunal de Justicia de 19 de junio de 1990, EU:C:1990:257, apartados 22-23.

${ }^{29}$ Mark Fenwick, y Stefan Wrbka, «The Shifting Meaning of Legal Certainty» en Legal Certainty in a Contemporary Context, ed. por Mark Fenwick, y Stefan Wrbka (Heidelberg: Springer, 2016), 2.

30 Aunque se puede reconocer una cierta regulación expresa del principio de seguridad jurídica o, como se ha dicho, de una codificación parcial, en particular en el art. 41 de la Carta de Derecho Fundamentales de la Unión Europea. Véase de Pablo Martín Rodríguez, «The principle of legal certainty and the limits to the applicability of EU law», Cahiers Droit Européen, n. ${ }^{\circ} 1$ (2016): 136; si bien debemos considerar - siguiendo a este autor - que tal y como está configurado en la Carta únicamente sería aplicable a las instituciones europeas, vinculando a los Estados miembros como un principio general, como el propio Tribunal de Justicia ha enfatizado en el Asunto C-249/13, Boudjlida, Sentencia del Tribunal de Justicia de 11 de diciembre de 2014, EU:C:2014:2431, apartados 30 y ss.

31 Stephen Weatherill, Law and Values in the European Union, op. cit., 133.

32 Martín Rodríguez plantea que metodológicamente podemos buscar e identificar cinco diferentes escenarios o situaciones legales de carácter funcionan donde el principio de seguridad jurídica puede jugar un papel de limitación de una plena aplicación del Derecho de la UE: limitando la validez de normas jurídicas, limitando su aplicación, limitando sus efectos interpretativos sobre otras normas, previniendo la reparación del incumplimiento del Derecho de la UE, o previniendo las consecuencias totales del incumplimiento del Derecho de la UE. Véase Pablo Martín Rodríguez, «The principle of legal certainty and the limits to the applica- 
No obstante, a pesar de la firmeza de una resolución administrativa, la seguridad jurídica tiene límites. Aunque inicialmente el Tribunal de Justicia pareció dar una relevancia determinante al principio de primacía frente a las resoluciones administrativas firmes ${ }^{33}$, en Kühne \& Heitz matiza esta cuestión, pues tiene oportunidad de afirmar la importancia del principio de seguridad jurídica, en relación con las resoluciones administrativas, afirmando que el derecho comunitario no exige per se que un órgano administrativo esté obligado, en principio, a reconsiderar una resolución administrativa que hubiera adquirido firmeza ${ }^{34}$, permitiendo por tanto una modulación del principio de primacía a través de la seguridad jurídica ${ }^{35}$. Se trata también, en definitiva, de dar una respuesta al necesario equilibrio con la interpretación uniforme del derecho de la $\mathrm{UE}^{36}$.

Así, en Kühne \& Heitz, constata que el órgano administrativo estará obligado a examinar de nuevo una resolución administrativa firme, para tener en consideración una interpretación del Tribunal de Justicia sobre una disposición de derecho europeo, cuando se dan las siguientes condiciones: a) dispone de esta facultad conforme al derecho interno, b) la resolución administrativa ha adquirido firmeza a raíz de una sentencia judicial $^{37}$, c) la sentencia judicial resuelve en última instancia basándose en

bility of EU law», op. cit., 130-139. Desde esta perspectiva nuestro estudio atendería en particular a los supuestos del cuarto escenario, pero, sin embargo, entendemos que es más preciso decir que nuestro objeto de atención es cuando la seguridad jurídica, y en particular la res iudicata, puede limitar la efectividad del derecho comunitario, y no la prevención de la reparación de su incumplimiento, pues al final reparación habrá vía responsabilidad patrimonial por incumplimiento. Y esto porque la falta de efectividad del derecho europeo se repara precisamente a través del recurso al mecanismo de la responsabilidad por incumplimiento, el derecho comunitario ha visto limitada su efectividad, pero no se ha limitado su reparación, simplemente ésta se produce por otras vías distintas.

33 Véase Asunto C-224/1997, Ciola, antes citado, apartados 25 y ss. En esta sentencia, como hemos señalado antes, el Tribunal de Justicia concreta que la primacía del Derecho de la UE no solo desplaza las disposiciones administrativas de carácter general, sino también las individuales y concretas, es decir, los actos administrativos contrarios al derecho comunitario, puesto que la primacía no dependería de la naturaleza de la disposición interna.

34 Asunto C-453/00, Kühne \& Heitz, Sentencia del Tribunal de Justicia de 13 de enero de 2004, EU:C:2004:17, apartado 24.

35 Véase en el mismo sentido, entre otros, Asunto C-2/08, Fallimento Olimpiclub, Sentencia del Tribunal de Justicia de 3 de septiembre de 2009, EU:C:2009:506.

${ }^{36}$ Giuseppe Martinico, The Tangled Complexity of the EU Constitutional Process (Londres y Nueva York: Routledge, 2013), 147.

37 Esto evidencia la conexión con la res iudicata, pues una resolución judicial ha confirmado una decisión administrativa y, por tanto, los propios efectos de la cosa juzgada protegerían la decisión administrativa; sin embargo, es una cuestión y una línea argumental que el Tribunal de Justicia va a preferir ignorar, como luego se analiza. 
una interpretación del derecho de la UE que a la luz de la jurisprudencia del Tribunal de Justicia posterior es errónea, y se ha adoptado sin someter cuestión prejudicial ante el mismo, y d) el interesado se dirige al órgano administrativo de forma inmediata después de tener conocimiento de la jurisprudencia del Tribunal de Justicia ${ }^{38}$; requisitos claramente restrictivos y difíciles de cumplir ${ }^{39}$, y que al estar fundados en el ordenamiento jurídico interno y corresponder a las autoridades nacionales la valoración de la situación concreta a la luz del mismo, puede tener repercusiones serias para los derechos de los individuos, y plantear dificultades en ciertos Estados miembros, con soluciones diversas ${ }^{40}$, que puede afectar en última instancia a una homogénea efectivad del derecho europeo en todo el territorio de la Unión Europea.

A pesar de que la sentencia trataba sobre la revisión de resoluciones administrativas firmes precisamente como consecuencia de una decisión judicial con efectos de cosa juzgada - que interpreta erróneamente el derecho comunitario - ${ }^{41}$, a diferencia del Abogado General Léger, que había aclarado en sus conclusiones que el derecho comunitario podía primar sobre la cosa juzgada, el Tribunal de Justicia prefirió no abordar la cuestión de los efectos de la primacía sobre la sentencia judicial ${ }^{42}$.

En diversas sentencias se confirma esta doctrina, e interesa destacar, por ejemplo, que en la sentencia Kempter, el Tribunal de Justicia concreta que no es necesario haber alegado o invocado el Derecho de la Unión en el marco del recurso judicial, así como que la revisión de la resolución administrativa firme no está sujeta, desde el punto de vista del derecho comunitario, a un límite temporal determinado si bien los Estados miembros sí pueden sujetarla a unos plazos razonables ${ }^{43}$. Ahora bien, ¿cómo afecta la primacía a la cosa juzgada, que está estrechamente vinculada con la seguridad jurídica?

38 Asunto C-453/00, Kühne \& Heitz, antes citado, apartados 27 y 28.

39 Damian Chalmers, Gareth Davies, y Giorgio Monti, European Union Law: Text and Materials (Cambridge: Cambridge University Press, 2014, 3. . edición), 95.

40 Xavier Groussot, y Timo Minssen, «Res Judicata in the Court of Justice Case Law: Balancing Legal Certainty with Legality?», European Constitutional Law Review, n. 3 (2007): 401.

${ }^{41}$ Se puede afirmar que se trata de la revocación por la Administración Pública de decisiones administrativas previas confirmadas judicialmente, y que por tanto afectan de forma únicamente indirecta a la decisión judicial. Véase Zsófia, «Retrial in the member States on the Ground of Violation of EU Law», ELTE Law Journal, n. 1 (2017): 55-98.

${ }^{42}$ Carsten Kremer, «Los límites de la cosa juzgada en el Derecho de la Unión Europea», Revista de Derecho de la Pontificia Universidad Católica de Valparaíso, n. ${ }^{\circ} 35$ (2010): 209, DOI: $10.4067 /$ S0718-68512010000200006.

43 Asunto C-2/06, Kempter, Sentencia del Tribunal de Justicia de 28 de febrero de 2008, EU:C:2008:78, apartados 46 y 60. 


\section{La cosa juzgada como límite a la primacía y efectividad del Derecho de la UE}

\section{Concepto y aproximación a la fuerza de cosa juzgada (res iudicata), y las líneas jurisprudenciales del Tribunal de Justicia sobre la misma}

El principio de seguridad jurídica, con todas sus particularidades, tiene como una de sus consecuencias características, en el Estado de Derecho, la llamada cosa juzgada (res iudicata), que es una institución jurídica de enorme interés en el derecho procesal, si bien su conceptualización y rasgos no son siempre de fácil precisión. En efecto, el principio del valor o la autoridad de la cosa juzgada forma parte del propio ordenamiento jurídico de la UE, aunque no ha sido objeto de regulación, pues el Tribunal de Justicia lo ha venido asumiendo como un principio propio de ese ordenamiento, que es además común a los sistemas jurídicos de los Estados miembros, aunque no siempre con el mismo significado ${ }^{44}$.

No obstante, podemos tratar de extraer algunos elementos esenciales. Así, cabe entender por fuerza de cosa juzgada los efectos que produce una sentencia (o una resolución equivalente) que es firme, y que implica que no es impugnable (cosa juzgada formal). Además, en el caso de que se haya resuelto sobre el fondo del asunto, en la medida en que la verdad real es per se inalcanzable, se habría alcanzado la verdad judicial, que es pro veritate habetur, por ello, la doctrina procesal, coincide en definir la cosa juzgada material como, no sólo, por un lado la imposibilidad de reiterar la solicitud o petición de tutela judicial enfrenta ante los tribunales, cuando sobre el asunto ya existe entre las mismas partes una respuesta judicial, sino también, por otro lado, la obligación de partir de esta respuesta cuando su contenido tenga una relación de dependencia, conexión o prejudicialidad con el litigio que se resuelve en procesos sucesivos (Calaza, 2011).

Desde luego, aunque la cosa juzgada forma parte del ordenamiento jurídico de la UE nos interesa en cuanto que cosa juzgada nacional ${ }^{45}$. Puede ocurrir que una decisión judicial nacional con fuerza de cosa juzgada haya vulnerado el Derecho de la Unión Europea, bien por error u omisión, o por-

${ }^{44}$ Véase Elisa Torralba-Mendiola y Elena Rodríguez-Pineau, «Two'S Company, Three'S a Crowd: Jurisdiction, Recognition and Res Judicata in the European Union», Journal of Private International Law, v. 10, n. ${ }^{\circ} 3$ (2014): 419, DOI:10.5235/17441048.10.3.403.

${ }_{45}$ El desarrollo del principio de cosa juzgada en el derecho procesal de la UE, sin duda también de interés, responde a las influencias de los derechos procesales nacionales, mayoritariamente el francés, véase Araceli Turmo, «La efectividad del Derecho de la Unión Europea como motivo de protección de la cosa juzgada nacional: nota sobre la sentencia de 24 de octubre de 2018, XC y otros», Revista de Derecho Comunitario Europeo, n. 63 (2019): 602603. 
que de forma manifiesta se ha pretendido hacerlo, la causa es lo de menos. Se suele entender que podemos vincular la cosa juzgada con diversas líneas jurisprudenciales del Tribunal de Justicia, tanto la referida a la responsabilidad del Estado miembro como la de la revisión de decisiones firmes ${ }^{46}$, o incluso también con la línea referida al recurso por incumplimiento ${ }^{47}$; pero aquí no interesa en estos momentos, o mejor dicho, nos interesan menos las eventuales consecuencias que el incumplimiento del derecho de la UE, aunque sea producto de una sentencia firme, puede producir desde el punto de vista de la responsabilidad del Estado miembro ${ }^{48}$ o respecto al procedimiento que por incumplimiento (procedimiento de infracción) podría iniciar la Comisión Europea, supuestos en los que parece que no hay una obligación de modificación de la decisión judicial más allá de la constatación del incumplimiento ${ }^{49}$; aunque sin duda hay una obligación de reparación por parte de las autoridades nacionales, es decir, de indemnizar por los daños causados y/o solucionar el incumplimiento para garantizar la efectividad del derecho europeo. Sin embargo, como se ha dicho con elocuencia la eventual responsabilidad por daños puede consolar en algunos casos, pero no repara la injusticia, e incluso en otros supuestos puede que no sirva de mucho cuando se mantiene una discriminación o se impide la efectividad de los derechos que se pretendían, y tampoco parece que esperar que la Comisión Europea eventualmente inicie un procedimiento de incumplimiento pueda ser relevante para el individuo ${ }^{50}$.

Ahora bien, aunque la regla general es que el principio de cosa juzgada supone una limitación a la primacía ${ }^{51}$, sí pueden existir ocasiones en las que, desde el punto de vista del derecho de la Unión, procede realizar en la pondera-

46 Xavier Groussot, y Timo Minssen, «Res Judicata in the Court of Justice Case Law: Balancing Legal Certainty with Legality?», op. cit., 386.

47 Véase Carsten Kremer, «Los límites de la cosa juzgada en el Derecho de la Unión Europea», op. cit., 200.

48 Asunto C-224/01, Köbler, Sentencia del Tribunal de Justicia de 30 de septiembre de 2003, EU:C:2003:513; y Asunto C-173/03, Sentencia del Tribunal de Justicia de 13 de Junio de 2006, Traghetti, EU:C:2006:391.

49 Es verdad que respecto al procedimiento de incumplimiento, una eventual declaración por parte del Tribunal de Justicia se plantean dificultades, como señala Kremer, y hay discusión en la doctrina sobre la existencia de efectos ex nunc de la eventual sentencia y si genera o no una obligación de corregir la sentencia que ha motivado el incumplimiento, si bien parece la mayoría de autores entiende que no se daría esta obligación, opinión que comparto. Véase Carsten Kremer, «Los límites de la cosa juzgada en el Derecho de la Unión Europea», op. cit., 200 y ss.

50 Alexander Kornezov, «Res Iudicata of National Judgements incompatible with EU Law: Time for a major rethink?», Common Market Law Review, v. 51, n. 3 (2014):810.

${ }^{51}$ En el sentido de que su capacidad más importante es la de impedir que la primacía despliegue sus efectos sobre el conflicto, véase Antonio López Escudero, «Primacía del Derecho de la Unión Europea y sus límites en la jurisprudencia reciente del TJUE», op . cit., 805. 
ción una eventual limitación de los efectos de la propia fuerza de cosa juzgada, como hemos visto antes con las resoluciones administrativas firmes. Porque, si bien es cierto que solucionar la ponderación con la prevalencia del principio de primacía llevaría al vaciamiento del valor de la cosa juzgada, tampoco es posible admitir una fuerza absoluta de la misma que dejaría sin efectividad al derecho de la UE, o haría, al menos que esa efectividad fuera irreconocible.

Por ello, a pesar de que la aproximación casuística puede afectar al propio principio de seguridad jurídica ${ }^{52}$, no es menos cierto que de momento no se ha encontrado una mejor solución, pero es posible tratar de identificar algunas reglas sistemáticas sobre la ponderación del conflicto ${ }^{53}$.

\section{La ponderación casuística entre primacía y efectividad del derecho de la UE y la fuerza de cosa juzgada}

En el caso Eco Swiss el Tribunal de Justicia ya tuvo ocasión de reconocer la justificación de que gozaban las normas nacionales que limitan la posibilidad de revisar un laudo arbitral con fuerza de cosa juzgada, por «los principios básicos del sistema jurisdiccional nacional, como los de seguridad jurídica y respeto de la cosa juzgada, que constituye su expresión», no obligando a no aplicar tales normas, aunque fuera necesario para examinar en un laudo arbitral posterior si el contrato declarado válido podía ser nulo desde el punto de vista del derecho comunitario ${ }^{54}$.

Esto ya anticipaba la respuesta que daría para un caso en el que se tratara de la fuerza de cosa juzgada de una resolución judicial. Es en Kapferer donde el Tribunal de Justicia, en un tema vinculado a la protección al consumidor ${ }^{55}$, tiene la oportunidad de enfrentarse a este problema: ¿El derecho de

52 Como pone de manifiesto el trabajo de Catherine Kessedjianm, «L'autorité de la chose jugée et l'effectivité du droit européen», ERA Forum, n. ${ }^{\circ} 11$ (2010): 263-279, DOI:10.1007/ s12027-010-0162-z.

${ }^{53}$ Hay que reconocer, por otro lado, que la metodología que se suele utilizar para el análisis jurisprudencial y la identificación de líneas jurisprudenciales es limitada por esencia. Se trata de métodos empíricos de búsqueda de sentencias por palabras clave, o teniendo en consideración guías jurisprudenciales o la literatura más relevante sobre el tema, pero esto no es sino una metodología de aproximación al caso, que si bien puede servir para el estudio de la realidad de una institución jurídica en la jurisprudencia, no deja de implicar el uso de reglas heurísticas, y por tanto, está afectada de las propias limitaciones intrínsecas al propio sistema metodológico.

${ }^{54}$ Asunto C-126/97, Eco Swiss, Sentencia del Tribunal de Justicia de 1 de junio de 1999, EU:C:1999:269, apartados 47 y 48.

55 Como veremos a lo largo de este trabajo, en varias ocasiones el Tribunal de Justicia se pronuncia sobre el principio de seguridad jurídica, y en particular sobre la fuerza de cosa juzgada en relación con la efectividad del derecho comunitario cuando se trata de garantizar la protección al consumidor. 
la UE obliga a inaplicar una disposición nacional que atribuye fuerza de cosa juzgada a una resolución para corregir una violación del derecho comunitario? La respuesta, no por más anticipada menos importante, es que no ${ }^{56}$.

La Sra. Kapferer, ciudadana austríaca, pretendía cobrar un premio de una sociedad alemana de venta por correo porque en un envío nominal dirigido a la primera, le había dado la impresión de que lo había obtenido, y lo reclamó en vía judicial. Aunque la sociedad alemana alegó la excepción de jurisdicción, el órgano judicial austríaco admitió la demanda, si bien resolvió sobre el fondo desestimando las peticiones de la Sra. Kapferer, que recurrió en apelación. El demandado no apeló porque, a pesar de que no se resolvió a su favor la excepción de jurisdicción, la resolución de instancia le había sido favorable en el fondo. El órgano judicial alemán que conoce de la apelación planteó una cuestión prejudicial ya que entendía que la cuestión de la aplicabilidad del foro del consumidor podía ser perjudicial para la demandada, y albergaba dudas de que una promesa de premio engañosa para la incitación de celebración de un contrato, pero de carácter preparatorio, presentara una relación suficientemente estrecha con la celebración de un contrato de consumo para determinar la competencia del foro del consumidor; sin embargo la sociedad alemana no impugnó esta cuestión, adquiriendo esta desestimación de la declinatoria fuerza de cosa juzgada respecto a la competencia internacional, pero pregunta si conforme al derecho comunitario podría examinar de nuevo esta cuestión, con el fundamento del principio de cooperación leal, y aplicando la doctrina Kühne $\& \operatorname{Heinz}^{57}$.

El Tribunal de Justicia recuerda la importancia del principio de fuerza de cosa juzgada en el ordenamiento jurídico comunitario y en los ordenamientos jurídicos nacionales, para garantizar tanto la propia estabilidad del Derecho como de las relaciones jurídicas, como de buena administración de justicia $^{58}$, citando las sentencia Köbler ${ }^{59}$ y constatando, como en Eco Wiss, que el derecho comunitario no obliga a no aplicar las normas internas que confieren fuerza de cosa juzgada aunque ello permitiera subsanar una vulneración del mismo, siempre que la regulación procesal interna respete los

56 Asunto C-234/04, Kapferer, Sentencia del Tribunal de Justicia de 16 de marzo de 2006, EU:C:2006:178.

57 Asunto C-234/04, Kapferer, citado supra, apartados 16 y 17.

58 Ibid., apartado 20.

59 Aquí el Tribunal de Justicia razona que la importancia de la fuerza de cosa juzgada - citando Eco Swiss - pero esto no excluye la responsabilidad de los Estados miembros por incumplimiento del derecho comunitario, que puede derivar de una resolución de un órgano jurisdiccional que resuelva en última instancia, y que no cuestiona la fuerza de cosa juzgada. Véase Asunto C-224/01, Köbler, ya citado, apartados 38 y 39. 
principios de equivalencia y de efectividad ${ }^{60}$; lo que no desvirtúa la doctrina Kühne \& Heitz, que podría ser aplicable por tanto no sólo a las decisiones administrativas firmes, sino también a las judiciales o, al menos queda abierta esta posibilidad a pesar de las diferencias notables existentes entre decisiones administrativas firmes y decisiones judiciales firmes, por la fuerza de cosa juzgada (res iudicata) de estas últimas, si bien condicionada a que la normativa procesal interna faculte al órgano judicial a examinar de nuevo la decisión firme ${ }^{61}$.

Pero aunque se ha razonado, en extenso, que parece que el Tribunal de Justicia no haya querido tomar una postura clara, dejando sin contestar si la doctrina de Kühne \& Heitz era aplicable a las decisiones judiciales ${ }^{62}$; lo cierto es que el desarrollo de la jurisprudencia del Tribunal de Justicia deja la puerta abierta a revisar las decisiones judiciales firmes con efectos de cosa juzgada, incluso sin los restrictivos requisitos establecidos en la doctrina Kühne \& Heitz, como vamos a ver más abajo ${ }^{63}$. No obstante, al depender de la legislación interna, y de la valoración que se haga del derecho interno por los jueces nacionales, puede llegar a tratarse de un supuesto de carácter excepcional, y por tanto de un sendero estrecho y tortuoso para la efectividad del derecho europeo.

Se ha considerado también por algunos relevantes autores que Kapferer «no ha encontrado aún un perfecto encaje en la jurisprudencia del Tribunal de Justicia», sobre todo desde el desarrollo de la línea jurisprudencial de Rheinmühlen $I^{64}$, que atribuye al juez nacional la facultad de plantear la cuestión prejudicial ante el Tribunal de Justicia incluso cuando de forma previa se haya pronunciado el tribunal nacional superior, y esta línea jurisprudencial confirmada en numerosas ocasiones no tendría un fácil encaje con los principios de seguridad jurídica y estabilidad normativa que se derivan de Kapferer, como planteó el Abogado General Cruz Villalón en Elchinov $^{65}$, o la línea jurisprudencial relativa a las ayudas del Estado donde el

60 Asunto C-234/04, Kapferer, cit., apartados 21 y 22.

${ }^{61} \mathrm{Ibid}$., apartado 23.

62 Véase en este sentido los trabajos de Xavier Groussot, y Timo Minssen, «Res Judicata in the Court of Justice Case Law: Balancing Legal Certainty with Legality?», op. cit., 408; y Carsten Kremer, «Los límites de la cosa juzgada en el Derecho de la Unión Europea», op. cit., 213.

${ }^{63}$ Pero se trata, en definitiva, de aprovechar todas las opciones existentes en derecho interno que faciliten la efectividad del Derecho de la UE, como muy bien ha dicho Araceli Turmo, «La efectividad del derecho de la Unión Europea como motivo de protección de la cosa juzgada nacional: nota sobre la sentencia de 24 de octubre de 2018, XC y otros», op. cit., 608.

64 Asunto C-166/73, Rheinmühlen I, Sentencia del Tribunal de Justicia de 16 de enero de 1974, EU:C:1974:3.

65 Asunto C-173/09, Elchinov, Conclusiones del Abogado General Cruz Villalón, EU:C:2010:581. 
Tribunal de Justicia «se ha mostrado vacilante a la hora de admitir que la fuerza de cosa juzgada de una sentencia nacional tenga efectos sobre el derecho de la Unión», manteniéndose aún esta tensión ${ }^{66}$.

Ciertamente el principio de fuerza juzgada tiene una compleja conjugación con estas líneas jurisprudenciales. Así, en Lucchini el Tribunal considera contraria al derecho comunitario la aplicación de una disposición nacional que consagra la fuerza de cosa juzgada cuando esta aplicación constituye un obstáculo para la recuperación de una ayuda de Estado concedida en incumplimiento del derecho comunitario, habiendo declarado de forma firme la Comisión Europea la incompatibilidad ${ }^{67}$.

Se ha subrayado que en Lucchini el Tribunal de Justicia no cita las referidas antes Kühne \& Heitz ni Kapferer, sino las sentencias Simmenthal y Factortame, a las que ya hemos hecho referencia en otro apartado, donde el conflicto se resuelve en favor de la efectividad del derecho comunitario, así la clave en Lucchini parece ser el aseguramiento de la distribución de competencias entre la Comisión y los tribunales de los Estados miembros ${ }^{68}$, siendo competencia exclusiva de la primera la determinación de la compatibilidad de las ayudas con el derecho europeo ${ }^{69}$, y por consiguiente de plena jurisdicción del Tribunal de Justicia ${ }^{70}$ y, además, no había otra opción para garantizar la efectividad derecho de la UE que limitar la fuerza de la cosa juzgada $^{71}$.

Si bien, en efecto, Lucchini ha sido objeto de críticas, sobre todo apuntando a la relevancia que podía tener un cambio de jurisprudencia que afectara a la intangibilidad de la cosa juzgada, también se ha considerado que era un caso con unas especiales características, comprendiendo que, además, el tribunal nacional había desatendido la importante normativa europea sobre ayudas de Estado ${ }^{72}$, y que incluso se podría identificar en el espíritu de la sen-

66 Daniel Sarmiento, El Derecho de la Unión Europea, op. cit., 322.

67 Asunto C-119/05, Lucchini, Sentencia del Tribunal de Justicia de 18 de julio de 2007, EU:C:2007:434, apartados 59-63.

68 Véase Pablo Martín Rodríguez, «Res judicata pro veritate habetur c. Primacía del Derecho comunitario: un combate por librar?», Revista Española de Derecho Europeo, n. ${ }^{\circ} 24$ (2007): 521-557, y del mismo autor «The principle of legal certainty and the limits to the applicability of EU law», op. cit., 134.

${ }^{69}$ Carsten Kremer, «Los límites de la cosa juzgada en el Derecho de la Unión Europea», op. cit., 214-215.

70 Xavier Groussot, y Timo Minssen, «Res Judicata in the Court of Justice Case Law: Balancing Legal Certainty with Legality?», op. cit., 414.

71 Carsten Kremer, «Los límites de la cosa juzgada en el Derecho de la Unión Europea», op. cit., 214-215.

72 Paolo Mengozzi, «La tutela davanti ai giudici nazionali dei diritti riconosciuti ai singoli ed i principi generali del diritto dell'Unione», Quaderni della Rivista- Il Diritto dell'Unione Europea (Milán: Giufrrè Editore, 2011), 82-83. 
tencia que el Tribunal de Justicia consideraba la sentencia nacional afectada como ultra vires, al no tener el juez nacional competencia para pronunciarse sobre la compatibilidad de la ayuda estatal con el mercado ${ }^{73}$.

Pero a pesar de sus especiales características no deja de ser reseñable que la primacía del derecho comunitario permita inaplicar normas procesales internas que atribuyen a una sentencia judicial fuerza de cosa juzgada y que impiden por tanto su revisión, para garantizar la efectividad del derecho de la UE.

Sin embargo, y dadas las particularidades del tema competencial, no parece que podamos extraer de Lucchini que, con carácter general, las condiciones establecidas en Kühne \& Heitz no son aplicables a la revisión, con carácter general, de decisiones judiciales; sino únicamente cuando estemos en un tema de competencia exclusiva de la Comisión Europea ${ }^{74}$.

En la interesante sentencia Fallimento Olimpiclub ${ }^{75}$, se dilucida precisamente si Lucchini había abierto la puerta a una tendencia jurisprudencia de relativizar el valor de la fuerza de la cosa juzgada. Se trataba de un asunto de IVA, y el juez remitente planteaba la aplicabilidad o no de la importante jurisprudencia del Tribunal de Justicia en materia de IVA (por todas, $\operatorname{Halifax})^{76}$, a un litigio sobre un ejercicio fiscal sobre el que no había recaído aún sentencia, pero al que conforme una disposición nacional le eran aplicables dos resoluciones judiciales firmes, con fuerza de cosa juzgada, que habían resuelto respecto de la misma sociedad dos ejercicios fiscales diferentes, y que podía motivar la no revisión de un eventual resultado contrario al derecho comunitario, en sectores distintos a las ayudas de Estado (como era el caso de Lucchini), en particular respecto al IVA y la posible elusión indebida del mismo.

Pues bien, en esta sentencia el Tribunal de Justicia recuerda la importancia del principio de fuerza de cosa juzgada, a fin de garantizar tanto la

73 Giuseppe Martinico, «Constructivism, Evolutionism and Pluralism: Europe's Constitutional Grammar», King's Law Journal, v. 20, n. ${ }^{\circ} 2$ (2009): 309-326; y del mismo autor, The Tangled Complexity of the EU Constitutional Process, op. cit., 147.

${ }^{74}$ En cambio, Groussot y Minssen sostienen, en cambio, que la revisión de decisiones administrativas y judiciales firmes, dada su diferente naturaleza son muy distintas, y no cabría una traslación, mutantis mutandis, de las condiciones de al ámbito de las decisiones judiciales, lo que quedaría acreditado en la contención del Tribunal de Justicia en Kapferer, así como en la propia Lucchini, donde se prefiere optar por seguir la estela de Simmenthal, excluyendo por descontado la aplicabilidad de la primera condición, esto es, que haya una facultad de revisión en la normativa interna respecto a un tema de competencia exclusiva de la Comisión Europea como ocurriría en Lucchini. Véase Xavier Groussot, y Timo Minssen, «Res Judicata in the Court of Justice Case Law: Balancing Legal Certainty with Legality?», op. cit., 416.

75 Asunto C-2/08, Fallimento Olimpiclub, cit.

76 Asunto C-255/02, Halifax y otros, Sentencia del Tribunal de Justicia de 21 de febrero de 2006, EU:C:2006:121. 
estabilidad del Derecho y de las relaciones jurídicas como la propia administración de justicia, que hace que no puedan impugnarse resoluciones judiciales que hayan adquirido firmeza, citando Köbler y Kapferer, de forma que el derecho de la UE no obliga a dejar de aplicar las normas procesales internas que atribuyen fuerza de cosa juzgada, aunque esto permitiera subsanar una vulneración del derecho de la Unión, y el sistema de aplicación del principio de fuerza de cosa juzgada se rige por el derecho interno, en virtud del principio de autonomía procesal, siempre condicionado a los principios de equivalencia y efectividad; apreciando el caso especial de Lucchini, que no puede poner en cuestión esto, porque se refería a una situación particular donde se discutían los principios de reparto competencial en materia de ayudas de Estado, que son competencia exclusiva ${ }^{77}$.

Sin embargo, aunque este planteamiento parece auspiciar la conservación de la fuerza de cosa juzgada, el Tribunal de Justicia realiza un análisis concreto de los efectos de estas dos sentencias, y más en particular de que su errónea apreciación podría tener como consecuencia la aplicación incorrecta de las normas comunitarias sobre prácticas abusivas en materia de IVA contraria al derecho comunitario, que se reproduciría en cada ejercicio fiscal, sin posibilidad de corrección, lo que lleva a que en estas circunstancias considere que se trata de obstáculos de un envergadura suficiente para que no estén razonablemente justificados por el principio de seguridad jurídica y sean contrarios al principio de efectividad ${ }^{78}$. Por ello, esta sentencia reviste una importancia determinante, al constituir una regla de excepción a la regla general de preservación de la cosa juzgada.

En la no menos interesante Impresa Pizzarotti ${ }^{79}$, en un caso de adjudicación de un contrato de obra pública, el Tribunal de Justicia, además de resolver la cuestión del concepto y naturaleza del contrato de obras, responde a la posibilidad de corregir una sentencia con efectos de cosa juzgada para su adecuación al derecho de la Unión. El órgano judicial que había planteado la cuestión prejudicial, consciente de que una resolución judicial previa suya con efectos de cosa juzgada podría haber eventualmente vulnerado el derecho europeo, pregunta si podría dejarla por ineficaz, o bien modularla dado que según su propia jurisprudencia puede - con determinados requisitos - completar su fallo en la ejecución dando lugar a lo que se llama cosa juzgada en formación progresiva ${ }^{80}$. La sentencia vuelve a insistir en la importancia de la cosa juzgada y que Lucchini es un caso muy par-

77 Asunto C-2/08, Fallimento Olimpiclub, cit., apartados 22-25.

78 Ibid., apartados 30-31.

79 Asunto C-213/13, Impresa Pizzarotti, Sentencia del Tribunal de Justicia de 10 de julio de 2014, EU:C:2014:2067.

${ }^{80}$ Ibid., apartados 53-55. 
ticular, y sostiene que el derecho de la UE no exige que un órgano nacional, como regla general, deba reconsiderar una resolución con carácter de cosa juzgada, si bien cuando las normas procesales nacionales lo permiten para restablecer la conformidad de la situación con el derecho interno, atendiendo a los principios de efectividad y equivalencia, también debe prevalecer esta posibilidad con el Derecho de la Unión en materia de contratos públicos de obras ${ }^{81}$. Pero esto no es sino una aplicación y desarrollo de la doctrina Kapferer, antes apuntada.

En Târșia ${ }^{82}$ insiste en que no hay, como regla general, una exigencia por parte del derecho de la UE que obligue, en aras de su efectividad, a inaplicar una norma procesal nacional que atribuye fuerza de cosa juzgada a una resolución, aunque con ello se pudiera subsanar el incumplimiento del derecho de la UE, recordando la importancia del principio de fuerza de cosa juzgada, y citando la sentencia Pizzaroti, salvo que en las normas procesales nacionales permitieran la revisión de la cosa juzgada, pues aplicando los principios de equivalencia y efectividad, sí debería restablecerse la conformidad con el derecho de la Unión ${ }^{83}$. Sin embargo, estos principios no se oponen a una regulación procesal como la nacional que no atribuye esta posibilidad al juez nacional en los procedimientos civiles, aunque sí lo haga en los administrativos ${ }^{84}$. En una línea similar a Târșia, también es destacable $X C$ y otros $^{85}$, donde el Tribunal de Justicia razona que los principios de equivalencia y efectividad no exigen tampoco al juez nacional que amplíe el ámbito de aplicación de una vía de recurso de derecho interno que permite la repetición de un procedimiento penal para los supuestos de violación del Convenio Europeo de Derechos Humanos ${ }^{86}$. Los razonamientos del Tribunal de Justicia en Târșia, y en XC y otros, manifiestan que la efectividad del derecho de la UE, y en particular la exijencia derivada del principio de equivalencia solo exige aplicar para el propio derecho de la UE las opciones que prevé el ordenamiento jurídico nacional para el propio dere-

81 Ibid., apartados 59-64.

82 Asunto C-69/14, Târșia, Sentencia del Tribunal de Justicia de 6 de octubre de 2015, EU:C:2015:662.

83 Ibid., apartados 28 y ss.

${ }^{84} \mathrm{Ibid}$., apartado 41; procedería para el restablecimiento el inicio de un procedimiento de responsabilidad patrimonial, apartado 40 de la sentencia, citando el Asunto C-224/01, Köbler, cit., apartado 34.

${ }_{85}$ Asunto C-234/17, XC y otros, Sentencia del Tribunal de Justicia de 24 de octubre de 2018, EU:C:2018:853.

$86 \mathrm{Ibid}$., apartados 54 y 55 . Para un análisis exhaustivo de esta sentencia se puede acudir al sugerente comentario de Araceli Turmo, «La efectividad del derecho de la Unión Europea como motivo de protección de la cosa juzgada nacional: nota sobre la sentencia de 24 de octubre de 2018, XC y otros», op. cit. 
cho interno en un procedimiento en un supuesto similar o equivalente, sin que sean trasladables las opciones de revisión previstas en otros procedimientos internos de distinto orden, o por violaciones de un derecho internacional $^{87}$.

También trata de la fuerza de la cosa juzgada en la conocía por sus efectos en España sentencia Gutiérrez Naranjo ${ }^{88}$, cuando el Tribunal de Justicia resuelve sobre la aplicabilidad de la Sentencia del Tribunal Supremo de 9 de mayo de $2003^{89}$ que limitaba los efectos de la declaración de nulidad de una cláusula suelo, por su carácter abusivo o falta de transparencia, integrada en los contratos de préstamos bancarios celebrados en España entre diversas entidades bancarias y consumidores. Si bien nuestro Tribunal Supremo había declarado que con carácter general las cláusulas suelo, esto es, aquellas cláusulas que establecen un límite o suelo a la bajada de tipo de interés en un contrato de préstamo bancario eran válidas, también estaban sujetas a un control de transparencia, debiendo el prestamista haber informado al consumidor respecto de su inclusión, llamando la atención sobre su existencia y estando la misma redactada de forma clara ${ }^{90}$, y determinó que en caso de falta de transparencia precedía la declaración de su nulidad y la restitución al consumidor; si bien estableció fundamentalmente dos límites: 1) que no afectaba dicha nulidad a las situaciones decididas de forma definitiva por resoluciones judiciales anteriores que hubieran adquirido autoridad de cosa juzgada, y 2) limitó los efectos temporales de la declaración a las otras situaciones no resueltas de forma definitiva, a partir de la fecha de la sentencia. Este segundo límite planteó dudas inmediatas, dado que la nulidad tiene efectos ex tunc, es decir, desde el origen, y lo que aplicaba el Su-

${ }^{87}$ Un poco distinta pero reseñable aquí por su conexión a lo comentado es $C a \breve{l i n}$, donde existiendo un procedimiento de revisión de resoluciones judiciales firmes en el derecho rumano por violación del Derecho de la UE, lo que se plantea es si una sentencia puede interpretar y condicionar esa revisión al plazo de un mes; entendiendo el Tribunal de Justicia, tras recordar la importancia de la cosa juzgada, que esto es compatible en principio con el Derecho de la UE, siempre que respete los principios de equivalencia y efectividad, pero este plazo preclusivo no era exigible en el caso particular que suscita la cuestión prejudicial, pues la afectada había interpuesto la demanda de revisión con antelación a la publicación de la sentencia que fijó el plazo aplicable, vinculando esta decisión al principio de seguridad jurídica y de confianza legítima. Vid. Asunto C-676/17, Călin, Sentencia del Tribunal de Justicia de 11 de septiembre de 2019, EU:C:2019:700, apartados 50-53.

88 Asuntos acumulados C-154/15, C-307/15 y C-308/15, Gutiérrez Naranjo, Sentencia del Tribunal de Justicia de 21 de diciembre de 2016, ECLI:EU:C:2016:980.

${ }^{89}$ Sentencia 241/2013, de la Sala de lo Civil del Tribunal Supremo, de 9 de mayo de 2003, recurso n. ${ }^{\circ}$ 485/2012, ROJ STS 1916/2013, ES:TS:2013:1916.

90 Véase Jesús Alfaro Águila-Real, «El Supremo ¿aclara? su sentencia sobre cláusulas-suelo en los préstamos hipotecarios», blog Derecho Mercantil España, 12 de junio de 2013, https://derechomercantilespana.blogspot.com/2013/06/el-supremo-aclara-su-sentencia-sobre.html 
premo era una limitación a los efectos de la declaración de nulidad; por ello se plantearon diversas cuestiones prejudiciales al respecto que se acumularon para ser resueltos en la citada sentencia del Tribunal de Justicia.

En esta sentencia lo que se dilucida es si el Supremo español estaba autorizado, ateniendo al derecho comunitario, y en particular a lo previsto en el art. 6.1 de la Directiva 93/13 ${ }^{91}$, que estipula que los Estados miembros establecerán que no vincularán al consumidor, en las condiciones estipuladas por el respectivo derecho nacional, las cláusulas abusivas que se celebren entre un consumidor y un profesional, tratándose de una disposición de orden público y de carácter imperativo, cuyo objetivo es lograr un equilibrio real entre las partes ${ }^{92}$; teniendo en consideración la importancia de que goza el interés público de la protección del consumidor ${ }^{93}$, lo que obliga al juez nacional a apreciar de oficio el carácter abusivo de una cláusula contractual y subsanar el desequilibrio ${ }^{94}$, recordando su importante doctrina de las facultades ex officio del juez nacional en materia de protección al consumidor ${ }^{95}$; lo que le lleva a interpretar esta disposición en el sentido de que se deduce en principio que una cláusula declarada abusiva nunca ha existido, y por tanto, no podrá tener efectos frente al consumidor, procediendo el restablecimiento de la situación de hecho y de Derecho ${ }^{96}$; y hay una remisión al derecho nacional, este no puede modificar la amplitud de protección ni su contenido sustancial cuestionando la protección más eficaz para el consumidor ${ }^{97}$.

Lo interesante es que el Tribunal de Justicia salva el primero de los límites establecidos por el Tribunal Supremo, es decir, el de las situaciones ya resueltas de forma definitiva por resolución judicial con efectos de cosa juzgada, pues la protección al consumidor no es absoluta, y también es importante la protección de la seguridad jurídica, citando la sentencia Asturcom Telecomunicaciones ${ }^{98}$ que no deja de ser una continuación de la doc-

91 Directiva (CEE) n. ${ }^{\circ}$ 93/13 del Consejo, de 5 de abril de 1993, sobre las cláusulas abusivas en los contratos celebrados con consumidores (DOCE L 95 de 21 de abril de 1993), pp. 29 a 34.

92 Asuntos acumulados C-154/15, C-307/15 y C-308/15, Gutiérrez Naranjo, cit., apartados 52-54.

93 Ibid., apartado 56.

${ }^{94}$ Ibid., apartado 58.

95 Véase Hans Micklitz, «Mohamed Aziz-sympathetic and activist, but did the court get it wrong?», ECLN Conference Florence When the ECJ gets it wrong, 30 de noviembre de 2014, 4-5, http://www.ecln.net/tl_files/ECLN/Florence\%202013/Micklitz\%20-\%20The\%20E CJ\%20gets\%20it\%20wrong\%20Aziz-30-11-14.pdf ; y Joaquín Sarrión Esteve, «Consumer», en Dictionary of Statuses within EU Law, ed. por Antonio Bartolini, Roberto Cippitani, y Valentina Colcelli (Heidelberg: Springer: 2019), 95-106.

96 Asuntos acumulados C-154/15, C-307/15 y C-308/15, Gutiérrez Naranjo, cit., apartado 61.

97 Ibid, apartado 65.

98 Asunto C-40/08, Asturcom Telecomunicaciones, Sentencia del Tribunal de Justicia de 6 de octubre de 2009, EU:C:2009:615, apartados 37-41. 
trina iniciada en Eco Swiss, y que viene a decir lo mismo que Kapferer pero respecto a los laudos arbitrales, quizá ésta otra era una cita más apropiada; pero lo curioso es que considera que la limitación temporal de los efectos merece un tratamiento diferente, y limita por tanto, la fuerza de cosa juzgada de la propia sentencia del Supremo, pues esta limitación equivale a privar con un carácter general al consumidor de las cantidades que hubiera abonado de forma indebida durante el periodo anterior al 9 de mayo de $2013^{99}$. En realidad, en Gutiérrez Naranjo podemos ver la continuación de Fallimento Olimpiclub, estamos ante una excepción a la regla general de preservación de la fuerza de cosa juzgada, de nuevo porque se trataría de una jurisprudencia contraria al derecho de la UE, con efectos generales o permanentes y que no quedaría reducida a unos casos concretos.

Poco después de esta importante sentencia, el Tribunal de Justicia aclarará en Banco Primus ${ }^{100}$ que la Directiva antes citada 93/13 no se opone a una norma nacional que impide al juez nacional realizar un nuevo examen de oficio del carácter abusivo de una cláusula cuando ya existe una resolución con fuerza de cosa juzgada que se ha pronunciado sobre la legalidad del conjunto de cláusulas del contrato en las que se integra, pero si el eventual carácter abusivo de la cláusula no ha sido aún examinado a través de un pronunciamiento con fuerza de cosa juzgada, el juez nacional estaría obligado a apreciar bien a instancia de las partes, bien de oficio, el carácter abusivo de la misma, cuando disponga de los elementos de hecho y de Derecho necesarios para ello ${ }^{101}$, y sería contrario al Derecho de la Uniónuna doctrina o jurisprudencia que impida este control con carácter general porque el profesional no haya llegado a aplicar la cláusula eventualmente abusiva y que derivaba del Tribunal Supremo español, pues las facultades del juez nacional de esta apreciación no pueden depender de esto ${ }^{102}$.

Este planteamiento me parece relevante porque, siguiendo a Guitiérrez Naranjo, el Tribunal de Justicia realiza en Banco Primus una clara ponderación entre la fuerza de cosa juzgada y el interés público de la protección del consumidor que respondería a la efectividad del derecho europeo, pues por un lado establece que corresponde respetar el pronunciamiento sobre el eventual carácter abusivo de una cláusula que ya haya adquirido fuerza de cosa juzgada, pero limita los efectos que puede tener una sentencia con cosa juzgada, pues se limita a aquellas cláusulas sobre las que se hubiera

99 Asuntos acumulados C-154/15, C-307/15 y C-308/15, Gutiérrez Naranjo, cit., apartados 69-73.

100 Asunto C-421/14, Banco Primus, Sentencia del Tribunal de Justicia de 26 de enero de 2017 , EU:C:2017:60.

101 Ibid., apartado 54.

102 Ibid, apartados 74 y 75. 
pronunciado la resolución, no pudiendo impedir que el juez nacional controle otras cláusulas sobre las que no hubiera habido pronunciamiento, ni tampoco establecer un tribunal, aunque sea supremo, una interpretación que con carácter general prive al juez nacional de las facultades de control que derivan del derecho comunitario, en este caso de la normativa en materia de protección al consumidor ${ }^{103}$.

Asimismo, la cosa juzgada tiene relevancia en un reciente asunto resuelto este mismo año, Telecom Italia $S p A^{104}$. La empresa Telecom Italia era la concesionaria en exclusiva del servicio público de telecomunicaciones en Italia, y por parte del Ministerio de Comunicaciones italiano se le requirió en su momento el pago de un importe económico en concepto de la liquidación del canon de concesión del ejercicio presupuestario 1997, así como otro importe en concepto del resto de liquidación del canon de concesión por el ejercicio presupuestario de 1998. No estando conforme, la empresa impugnó este requerimiento ante el tribunal administrativo regional de El Lacio, que planteo una cuestión prejudicial ante el Tribunal de Justicia que resolvió el asunto en la sentencia Telecom Italia en 2008, declarando que el derecho comunitario se oponía a que un Estado miembro exigiera a un operador, antiguo titular de un derecho exclusivo en servicios de telecomunicaciones públicas, el pago de una carga correspondiente al importe de contraprestación por el derecho exclusivo durante un año desde la fecha última prevista para la adaptación del derecho nacional a la normativa europea, que era el 31 de diciembre de $1998^{105}$; sin embargo, el órgano nacional remitente dictó una sentencia que declaró exigible el pago, sentencia que fue confirmada por el Consiglio di Stato. Dado el perjuicio provocado por esta decisión, Telecom Italia solicitó la inexigibilidad de los importes reclamados y que no se reconozca la eficacia de la cosa juzgada de la decisión judicial del Consiglio di Stato, y albergando dudas sobre esta cuestión, el juez nacional que conoce de la pretensión plantea esta cuestión prejudicial. La sentencia del Tribunal de Justicia constata que el Derecho de la Unión es contrario a una normativa nacional que prorroga el pago antes referido ${ }^{106}$. No obstante, vuelve a recordar, a falta de

103 Es importante reseñar, aunque no es objeto de este estudio, que el Tribunal Constitucional español estimó un recurso de amparo por vulneración del derecho fundamental a la tutela judicial efectiva porque el órgano judicial español, en este caso un juzgado de Primera Instancia, no atendió a la doctrina establecida en la sentencia Banco Primus, ni planteó cuestión prejudicial al respecto, en un procedimiento de ejecución hipotecaria. Véase Sentencia del Tribunal Constitucional n. ${ }^{\circ}$ 31/2019, de 28 de febrero, rec. 1086/2018, ES:TC:2019:31.

104 Asunto C-34/19, Telecom Italia SpA, Sentencia del Tribunal de Justicia de 4 de marzo de 2020, EU:C:2020:148.

105 Asunto C-297/06, Telecom Italia, Sentencia del Tribunal de Justicia de 21 de febrero de 2008, EU:C:2008:106.

106 Asunto C-34/19, Telecom Italia SpA, cit., apartado 52. 
normativa de la Unión, la relevancia del principio de fuerza de cosa juzgada que se rige por el ordenamiento interno de los Estados miembros, conforme a la autonomía procesal, si bien sujetándose a los principios de equivalencia y efectividad, citando Fallimento Olimpiclub ${ }^{107}$, e interpretando el derecho interno, toma en consideración todo el ordenamiento, para apreciar en qué medida puede aplicarlo de forma que no sea contrario al derecho europeo ${ }^{108}$.

Así, estamos ante una ponderación en la que la sentencia atribuye al juez nacional la valoración de si conforme al derecho interno es posible que la fuerza de cosa juzgada de la sentencia del Consiglio di Stato no sea determinante, tiene la obligación de garantizar la plena eficacia del derecho de la UE, dejando inaplicada una interpretación que no es compatible con el mismo ${ }^{109}$, pero si considera que conforme al derecho interno la fuerza de cosa juzgada que reviste la sentencia del Consiglio di Stato despliega sus efectos sobre el asunto que debe resolver, no estaría obligado a dejar de aplicar estas normas procesales nacionales ${ }^{110}$, quedando abierta la vía de la responsabilidad del Estado para remediar la violación del derecho europeo $^{111}$.

En la misma línea, en Hochtief Solutions ${ }^{112}$, un caso de licitación de contratos públicos, el Tribunal de Justicia había insistido en que si las normas procesales nacionales aplicables establecen la posibilidad de que el juez nacional reconsidere una decisión con fuerza de cosa juzgada para restablecer la conformidad de la situación, lo debe hacer, conforme a los principios de equivalencia y efectividad; pero interesa aquí más esta sentencia por otra cuestión, y es la que atañe al mecanismo de la responsabilidad del Estado por incumplimiento del derecho de la UE, que como hemos anticipiado, es una de las vías para lograr la efectividad del mismo o restablecerla, pues se puede topar también con la cosa juzgada. Así ocurre precisamente en una de las cuestiones que se plantean en Hochtief Solutions, y el Tribunal de Justicia manifiesta que la responsabilidad por los daños causados por un órgano nacional que ha resuelto en última instancia violando el derecho de la UE, se rige por los requisitos establecidos en la jurisprudencia del Tribunal de Justicia en Köbler - aunque pueden establecerse por el derecho interno requisitos menos restrictivos - y no excluye esta responsa-

107 Ibid., apartado 58.

108 Ibid., apartado 59. Véase al respecto el Asunto C-554/14, Ognyanov, Sentencia de 8 de noviembre de 2016, EU:C:2016:835, apartados 59-66.

109 Ibid., apartados 59 y 63.

110 Ibid., apartados 64-66.

111 Ibid., apartado 67-69.

112 Asunto C-620/17, Hochtief Solutions AG Magyarországi Fióktelepe, Sentencia del Tribunal de Justicia de 29 de julio de 2019, EU:C:2019:630. 
bilidad el hecho de que la propia sentencia que produce la violación tenga fuerza de cosa juzgada ${ }^{113}$.

También es interesante considerar la fuerza de carácter vinculante que puede tener una sentencia penal en un proceso civil, cuando dicha sentencia firme es incompatible con el derecho de la UE, pero el derecho interno o su interpretación le atribuye fuerza vinculante y obliga al juez civil a dictar una sentencia conforme a la misma, y ello puede generar lógicamente una nueva sentencia contraria al derecho de la UE. A este problema se enfrenta el Tribunal de Justicia en la reciente sentencia $C R N P A C^{114}$, donde una compañía aérea había sido condenada en sentencia firme, de forma incompatible con el Derecho de la UE, y el juez civil se plantea si la obligación de seguir la fuerza vinculante de la sentencia judicial en el sentido de imponer a dicho empresario una obligación de indemnizar a los trabajadores o a un organismo de pensiones nacional como víctimas de fraude sería conforme con el Derecho de la UE; el tribunal razona que esta fuerza vinculante de la cosa juzgada penal en el ámbito civil es contraria a la efectividad del derecho de la Unión ${ }^{115}$.

En definitiva, quizá el complejo puzle actualmente existente en la ponderación entre el principio de fuerza de cosa juzgada y la efectividad del Derecho de la Unión - que incorpora tanto la tutela de los derechos individuales, como también el tema de las competencias exclusivas y la plena jurisdicción del Tribunal de Justicia - deriva de una aproximación ciertamente casuística, pero respecto de la que podemos tratar de inferir, identificar, y proponer a consideración, algunas reglas prácticas:

1. Como regla general, la fuerza de cosa juzgada limita la posibilidad de revisar decisiones judiciales firmes (Kapferer, Impresa Pizzarotti, Târșia, XC y otros, etc.) e incluso laudos arbitrales (Eco Swiss, Asturcom), que gocen de esos efectos conforme a la normativa procesal nacional, siempre que se respeten los principios de equivalencia y efectividad, aunque tal revisión fuera necesaria para invalidar una decisión contraria al derecho europeo subsanando de esta forma la vulneración. Así, la efectividad de este y la eventual reparación habría que buscarla por parte de los individuos a través de la responsabilidad por incumplimiento del derecho comunitario (Köbler, no pudiendo verse limitada esta responsabilidad porque

113 Ibid., apartados 37-39.

114 Asuntos acumulados C-370/17 y C-37/18, CRNPAC, Sentencia de 2 de abril de 2020, EU:C:2020:260.

$115 \mathrm{Y}$ es que una cosa es que no se revise la sentencia penal, y otra que la interpretación de la fuerza de la cosa juzgada de la sentencia haga imposible o muy difícil en la práctica la efectividad del Derecho de la UE incluso en el ámbito civil, véase apartados 92 y ss. Asuntos acumulados C-370/17 y C-37/18, CRNPAC, cit. supra. 
la violación la produzca una sentencia con fuerza de cosa juzgada como indica Hochtief Solutions), y en caso de que no se corrija a futuro la norma que facilite la vulneración, la Comisión Europea tendría el mecanismo del procedimiento de infracción.

2. No obstante, si la normativa procesal nacional, o incluso la jurisprudencia nacional aplicable, permite la revisión o corrección de una decisión judicial con fuerza de cosa juzgada por vulneración del derecho interno, en un supuesto equivalente, el Tribunal de Justicia entiende que la efectividad debe prevalecer y por tanto faculta al juez para que revise esa decisión con fuerza de cosa juzgada para reparar una vulneración del derecho de la UE, y por tanto darle efectividad (Impresa Pizzarotti, Telecom Italia SpA, Hochtief Solutions), siendo por tanto incluso más flexible a la hora de atribuir o facultar al juez nacional para este control que lo es con los requisitos estrictos establecidos en Kühne \& Heitz sobre revisión de decisiones administrativas firmes, sin perjuicio de que, esta valoración del juez nacional, al depender lo puede convertir en un supuesto excepcional.

3. Asimismo, cuando existe una doctrina jurisprudencial, con fuerza de cosa juzgada conforme a las normas procesales nacionales, que conlleva no sólo a una violación puntual del derecho europeo, sino a impedir de forma generalizada en el tiempo la efectividad del mismo, estaríamos ante obstáculos de un envergadura suficiente para que no estén razonablemente justificados por el principio de seguridad jurídica y sean contrarios al principio de efectividad ( $\mathrm{Fa}$ llimento Olimpiclub, Gutiérrez Naranjo, Banco Primus), por lo que procedería su revisión, incluso aunque las normas procesales nacionales no lo permitieran. Asimismo, y en términos similares, habría que considerar que la pretendida fuerza vinculante de una sentencia contraria al derecho de la UE no debe tener efectos a la hora de dictar otra sentencia que haría prácticamente imposible la efectividad del derecho de la UE (como ocurre en CRNPAC, respecto de la fuerza vinculante de una sentencia penal dictada en contra del derecho de la UE respecto a un procedimiento civil posterior).

4. Por último, cuando se trata de un caso donde haya competencia exclusiva europea, y, por tanto, jurisdicción plena del Tribunal de Justicia, una decisión judicial nacional, aunque sea firme y tenga efectos de cosa juzgada conforme a la normativa procesal nacional, al vulnerar el derecho europeo sería - aunque el Tribunal de Justicia no lo manifieste así- ultra vires, y, por tanto, procedería su revisión, al carecer el juez nacional de competencia para pronunciarse (Lucchini). 


\section{Consideraciones finales}

Siendo la primacía la dovela central sobre la que descansa la arquitectura del derecho de la UE, la jurisprudencia del Tribunal de Justicia recuerda de forma constante la importancia del principio de fuerza de cosa juzgada, para garantizar tanto la propia estabilidad del Derecho como de las relaciones jurídicas.

Así, y en la medida en que no existe una regulación europea sobre la fuerza de la cosa juzgada, corresponde a los Estados miembros, en virtud del principio de autonomía procesal su regulación, siempre que respete en lo que atañe al derecho europeo los principios de equivalencia y efectividad.

No obstante, la primacía, y la propia preservación de la efectividad del ordenamiento jurídico de la UE, exige que un conflicto entre normas europeas con efecto directo y normas nacionales se resuelva con el desplazamiento o inaplicación de las últimas. Sin embargo, no siempre es así, y en ocasiones el operador jurídico, incluso un juez nacional, o bien no interpreta el derecho nacional de conformidad con el europeo, o en caso de conflicto no lo resuelve correctamente.

Las decisiones judiciales incompatibles con el derecho de la UE que adquieren fuerza de cosa juzgada plantean el problema de la ponderación entre la seguridad jurídica de la cosa juzgada nacional con la efectividad del propio derecho europeo. El Tribunal de Justicia ha resuelto de forma casuística estos conflictos. Y en este trabajo hemos tratado de realizar una aproximación a este puzle, que, es innegable, parece un difícil cubo de $\mathrm{Ru}$ bik; y hemos tratado, con mayor o menor acierto, de inferir y proponer algunas reglas prácticas que sirvan al operador jurídico.

De este estudio se deduce que, como regla general, la fuerza de cosa juzgada limita la posibilidad de revisar decisiones judiciales firmes (Kapferer, Impresa Pizzarotti, Târşia, XC y otros, etc.) e incluso laudos arbitrales (Eco Swiss, Asturcom), que gocen de estos efectos conforme a la normativa procesal nacional, siempre que se respeten los principios de equivalencia y efectividad. Esto es así, aunque la revisión fuera necesaria para invalidar una decisión contraria al derecho europeo subsanando de esta forma la vulneración.

La efectividad del mismo y la eventual reparación habría que buscarla

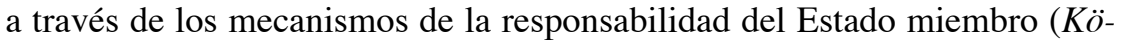
bler) que, por cierto, no podría limitarse porque la violación la produjera una sentencia con efectos de cosa juzgada (Hochtief Solutions); o bien en el supuesto de que la decisión judicial se base en una norma jurídica la corrección de la misma. Siempre quedaría también el mecanismo del procedimiento de infracción que podría activar la Comisión Europea.

No obstante, también hemos considerado la existencia de tres excepciones a esta regla general, donde se limita la eficacia de la fuerza de cosa juzgada: 
a) Si la normativa procesal nacional (o su interpretación) permite la revisión o corrección de una decisión judicial con fuerza de cosa juzgada por vulneración del derecho interno en un supuesto equivalente, el Tribunal de Justicia entiende que la efectividad debe prevalecer y por tanto el juez nacional debe revisar esa decisión con fuerza de cosa juzgada para reparar una vulneración del derecho de la UE, y por tanto darle efectividad (Impresa Pizzarotti, Telecom Italia SpA, Hochtief Solutions), siendo por tanto incluso más flexible para este control que lo es con los requisitos estrictos establecidos en Kühne \& Heitz sobre revisión de decisiones administrativas firmes, sin perjuicio de que, esta valoración del juez nacional, al depender lo puede convertir en un supuesto excepcional.

b) Asimismo, cuando existe una doctrina jurisprudencial, con fuerza de cosa juzgada conforme a las normas procesales nacionales, que conlleva no sólo a una violación puntual del derecho europeo, sino a impedir de forma generalizada en el tiempo la efectividad del mismo, estaríamos ante obstáculos de un envergadura suficiente para que no estén razonablemente justificados por el principio de seguridad jurídica y sean contrarios al principio de efectividad ( $\mathrm{Fa}$ llimento Olimpiclub, Gutiérrez Naranjo, Banco Primus), por lo que procedería su revisión, incluso aunque las normas procesales nacionales no permitan una revisión de la cosa juzgada; o bien en términos similares, habría que considerar que la pretendida fuerza vinculante de una sentencia contraria al derecho de la UE no debe tener efectos a la hora de dictar otra sentencia que haría prácticamente imposible la efectividad del derecho de la UE (CRNPAC).

c) Por último, cuando se trata de un caso donde haya competencia exclusiva europea, y, por tanto, de jurisdicción plena del Tribunal de Justicia, una decisión judicial nacional, aunque sea firme y tenga efectos de cosa juzgada conforme a la normativa procesal nacional, al vulnerar el derecho europeo sería - aunque el Tribunal de Justicia no lo manifieste así- ultra vires, y procedería su revisión, al carecer el juez nacional de competencia para pronunciarse (Lucchini).

\section{Sobre el autor}

Joaquín Sarrión Esteve es Licenciado en Derecho con Premio Extraordinario por la Universidad de Valencia. Doctor en Derecho de la Unión Europea por la Universidad de Bolonia desde 2011 (Premio de la Real Academia de Doctores de España) y Master en Unión Europea por la UNED. 
Actualmente es Investigador Ramón en la UNED, donde además imparte docencia de Derecho Constitucional y es Vicesecretario General de Asuntos Jurídicos.

Participa en diversos proyectos y grupos de investigación a nivel nacional e internacional, y es autor de diversas publicaciones y trabajos de investigación, habiendo obtenido algunos premios de investigación como el Premio Internacional Jurídico ISDE-FIA en Derecho Internacional (2012), Premio de Investigación Derechos Humanos Pastor Delgado Hernández (2012), o el II. ${ }^{\circ}$ Premio Internacional de Investigación en Derechos Humanos Joaquín Ruíz Giménez (Fundación Gregorio Peces Barba, 2011).

\section{About the author}

Joaquín Sarrión Esteve holds a degree in Law with Extraordinary Award from the University of Valencia. PhD in European Union Law by the University of Bologna since 2011 (Award Award of Royal Academy of Spanish Doctors). Master in European Union by the UNED. Actually is Ramóny Cajal Senior Research Fellow at UNED, where he also teaches Constitutional Law and works as General vicesecretary in legal issues.

He participates in several national and international research groups. Author of several publications and research works, he won several research awards as the International Law Award ISDE\&FIA (2012), the Pastor Delgado Hernandez Award in Human Rights (2012), and the IInd International Award Joaquín Ruiz Giménez in Human Rights (Gregorio Peces Barba Foundation, 2011). 


\section{Derechos de autor}

Los derechos de autor (para la distribución, comunicación pública, reproducción e inclusión en bases de datos de indexación y repositorios institucionales) de esta publicación (Cuadernos Europeos de Deusto, CED) pertenecen a la editorial Universidad de Deusto. El acceso al contenido digital de cualquier número de Cuadernos Europeos de Deusto es gratuito inmediatamente después de su publicación. Los trabajos podrán leerse, descargarse, copiar y difundir en cualquier medio sin fines comerciales y según lo previsto por la ley; sin la previa autorización de la Editorial (Universidad de Deusto) o el autor. Así mismo, los trabajos editados en CED pueden ser publicados con posterioridad en otros medios o revistas, siempre que el autor indique con claridad y en la primera nota a pie de página que el trabajo se publicó por primera vez en CED, con indicación del número, año, páginas y DOI (si procede). Cualquier otro uso de su contenido en cualquier medio o formato, ahora conocido o desarrollado en el futuro, requiere el permiso previo por escrito del titular de los derechos de autor.

\section{Copyright}

Copyright (for distribution, public communication, reproduction and inclusion in indexation databases and institutional repositories) of this publication (Cuadernos Europeos de Deusto, CED) belongs to the publisher University of Deusto. Access to the digital content of any Issue of Cuadernos Europeos de Deusto is free upon its publication. The content can be read, downloaded, copied, and distributed freely in any medium only for non-commercial purposes and in accordance with any applicable copyright legislation, without prior permission from the copyright holder (University of Deusto) or the author. Thus, the content of CED can be subsequently published in other media or journals, as long as the author clearly indicates in the first footnote that the work was published in CED for the first time, indicating the Issue number, year, pages, and DOI (if applicable). Any other use of its content in any medium or format, now known or developed in the future, requires prior written permission of the copyright holder. 